\title{
HIGH HEAT FLUX TEST WITH HIP BONDED 35X35X3 BE/CU MOCKUPS FOR THE ITER BLANKET FIRST WALL
}

\author{
DONG WON LEE ${ }^{1 *}$, YOUNG DUG BAE ${ }^{1}$, SUK KWON KIM ${ }^{1}$, HYUN KYU JUNG ${ }^{1}$, JEONG YONG PARK $^{1}$, \\ YONG HWAN JEONG ${ }^{1}$, BYUNG KWON CHOI ${ }^{1}$, and BYOUNG-YOON KIM ${ }^{2}$ \\ ${ }^{1}$ Korea Atomic Energy Research Institute \\ Daedeokdaero 1045, Yuseong-gu, Daejeon, 305-600, Republic of Korea \\ ${ }^{2}$ National Fusion Research Institute \\ Gwahangno 113, Yuseong-gu, Daejeon, 305-333, Republic of Korea \\ *Corresponding author. E-mail : dwlee@kaeri.re.kr
}

Received July 05, 2010

Accepted for Publication August 26, 2010

To develop the manufacturing methods for the blanket first wall (FW) of the International Thermonuclear Experimental Reactor (ITER) and to verify the integrity of the joint, Be/Cu mockups were fabricated and tested at the KoHLT-1 (Korea Heat Load Test facility), a graphite heater facility located at the Korea Atomic Energy Research Institute (KAERI). Since Be and $\mathrm{Cu}$ joining is the focus of the present study, the fabricated mockups had a CuCrZr heat sink joined with three Be tiles as an armor material, unlike the original ITER blanket FW, which has a stainless steel structure and coolant tubes. Hot isostatic pressing (HIP) was carried out at $580{ }^{\circ} \mathrm{C}$ and $100 \mathrm{MPa}$ for 2 hours as the method for Be/Cu joining. Three interlayers, namely, $1 \mu \mathrm{mCr} / 10 \mu \mathrm{mCu}, 1 \mu \mathrm{mTi} / 0.5 \mu \mathrm{mCr} / 10 \mu \mathrm{mCu}$, and $5 \mu \mathrm{mTi} / 10 \mu \mathrm{mCu}$ were applied as a coating to the Be tiles by a physical vapor deposition (PVD) method. A shear test was performed with the specimens, which were fabricated by the same methods as those used to fabricate the mockups. The average values were $125 \mathrm{MPa}$ to $180 \mathrm{MPa}$, and the samples with the $1_{\mu \mathrm{m}} \mathrm{Cr} / 10_{\mu \mathrm{m}} \mathrm{Cu}$ interlayer showed the lowest value. No defect or delamination was found in the joints of the mockups by the developed ultrasonic test using a flat-type probe with a $10 \mathrm{MHz}$ frequency and a 0.25 inch diameter. High heat flux (HHF) tests were performed at $1.0 \mathrm{MW} / \mathrm{m}^{2}$ heat flux for each mockup using the given conditions, and the results were analyzed by ANSYS-CFX code. For the test criteria, an expected fatigue lifetime about 1,000 cycles was obtained by analysis with ANSYS-mechanical code. Mockups using the interlayers of $1 \mu \mathrm{m} \mathrm{Ti} / 0.5 \mu \mathrm{m} \mathrm{Cr} / 10_{\mu \mathrm{m}} \mathrm{Cu}$ and $5 \mu \mathrm{m} \mathrm{Ti} / 10_{\mu \mathrm{m}} \mathrm{Cu}$ survived up to 1,100 cycles over the required number of cycles. However, one of the Be tiles in the other two mockups using the $1 \mu \mathrm{mCr} / 10 \mu \mathrm{mCu}$ interlayer was detached during the screening test, and others were detached by discharge after 862 cycles. The integrity of the joints using the proposed interlayers was proven by the HHF test, but the other interlayer requires more study before it can be used for the joining of $\mathrm{Be}$ to $\mathrm{Cu}$. Moreover, it was confirmed that the measured temperatures agreed well with the analysis temperatures, which were used to estimate the lifetime and that the developed facility showed its capability of the long time operation.

KEYWORDS : ITER; First Wall; HIP; Be/Cu Mockup; HHF Test

\section{INTRODUCTION}

The blanket first wall (FW) of the International Thermonuclear Experimental Reactor (ITER) is an important component which faces the plasma directly; therefore, it is subjected to high heat and neutron loads, in whichthe surface heat flux and volumetric heating due to a neutron wall loading are about $0.3 \mathrm{MW} / \mathrm{m}^{2}$ and $15 \sim 20 \mathrm{MW} / \mathrm{m}^{3}$, respectively. To endure such harsh conditions, the $\mathrm{FW}$ is composed of a beryllium (Be) layer as a plasma facing material, a copper alloy ( $\mathrm{CuCrZr}$ ) layer as a heat sink, and type 316L austenitic stainless steel (SS316L) as a structure as shown in Fig. 1 [1]. Since Korea is participating in the ITER project and is responsible for the procurement

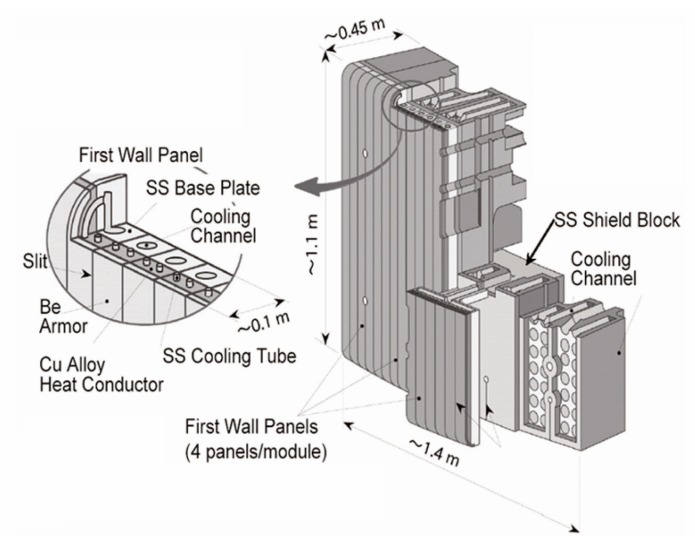

Fig. 1. Design and Composition of the ITER Blanket FW 
of about $10 \%$ of the ITER blanket FW, a manufacturing method needs to be developed. Moreover, the ITEROrganization introduced the following qualification program for the participating countries, including the EU, the USA, Japan, China, Russia, and Korea, because the blanket FW is an important component for safety. Two $80 \times 80 \times 3$ $\mathrm{Be} / \mathrm{Cu} / \mathrm{SS}$ mockups should be submitted, and a high heat flux (HHF) test will be performed under the $0.625 \sim 0.875$ $\mathrm{MW} / \mathrm{m}^{2}$ heat flux for 12,000 cycles, considering the ITER operation conditions and lifetime of the FW. The dimensions of Be tiles should be $80-\mathrm{mm}$ long, $80-\mathrm{mm}$ wide, $10-\mathrm{mm}$ thick. The $\mathrm{Cu}$ block should be $244-\mathrm{mm}$ long, $80-\mathrm{mm}$ wide, 25-mm thick with two cooling tubes (10-mm ID, SS316L), and the SS block should be 244-mm long, 80-mm wide, 25-mm thick with cooling holes (20-mm ID). To obtain the procurement qualification, the joints of $\mathrm{Be} / \mathrm{Cu}$ and $\mathrm{Cu} / \mathrm{SS}$ in the mockups should show no detachment or delamination during or after the test.

To prepare for the qualification program and to obtain the procurement eligibility, the manufacturing methods for the FW are being developed in Korea. Various joining methods have been investigated for the improvement of the bonding performance between $\mathrm{Be}$ tile and $\mathrm{Cu}$ alloy, and $\mathrm{Cu}$ alloy and SS block, respectively. Finally, the hot isostatic pressing (HIP) bonding method was chosen in consideration of the complex geometry of the FW. Various samples, such as $\mathrm{Cu} / \mathrm{SS}$ and $\mathrm{Be} / \mathrm{Cu}$ blocks with coated $\mathrm{Be}$ tile were fabricated and mechanical tests were performed to find an optimized bonding condition [2-3]. Various mockups with different dimensions and coating layers were fabricated to find an optimized bonding condition and canning methods for the HIP. Also, cyclic HHF tests were performed for the validation of the mockups' joining integrities with the various test facilities: $\mathrm{Cu} / \mathrm{SS}$ mockups test at JEBIS (JAEA electron beam irradiation stand, Japan), $\mathrm{Be} / \mathrm{Cu}$ mockups test in the Tsefey facility (Russia), and $\mathrm{Be} / \mathrm{Cu} / \mathrm{SS}$ mockups test in JUDITH-1 (JUelich DIvertor
Test facility in Hot cells, Germany) [4-7]. In the previous works, the optimum HIP conditions, such as temperature, pressure, duration time, and post- HIP heat treatment (PHHT) were found, as shown in Fig. 2, and several interlayers have been proposed.

In the present study, the mockups with three Be tiles and the proposed interlayers were fabricated and tested at athe newly developed facility, the Korea Heat Load Test (KoHLT-1) facility, in order to prepare the mockups for the qualification. The fabrication procedure, analysis results for determining the test conditions, and HHF test results are summarized in the following sections.

\section{FABRICATION OF THE BE/CU MOCKUPS}

Six mockups were fabricated according to the developed procedure and HIP conditions as shown in Figures 2 and 3. First, Be tiles and $\mathrm{Cu}$ block were prepared with the following dimensions. The Be tiles were 35.5-mm-long, 35.5-mmwide, and 10-mm-thick. The Cu block was 134.5-mm-long, 36-mm-wide, and 23-mm-thick with cooling holes (12.7$\mathrm{mm}$ ID). Three kinds of interlayers, namely, $1 \mu \mathrm{mCr} / 10 \mu \mathrm{mCu}$, $1 \mu \mathrm{m} \mathrm{Ti} / 0.5 \mu \mathrm{m} \mathrm{Cr} / 10 \mu \mathrm{mCu}$, and $5 \mu \mathrm{m} \mathrm{Ti} / 10 \mu \mathrm{m} \mathrm{Cu}$ were applied as a coating to the Be tiles which was mechanically polished down to a surface roughness of less than $\mathrm{R}_{\mathrm{a}} 1 \mathrm{~m}$. Before coating, ion etching was performed to clean the Be surface to remove $\mathrm{BeO}$ for easier deposition of the interlayers. Four SS 304 canning plates were TIG-welded to each other to surround the mockups, and degassing was performed at $400{ }^{\circ} \mathrm{C}$ for 2 hours up to a level of $10^{-5}$ torr through the evacuation pipe, which was connected to one canning plate. In a high-temperature high-pressure furnace, HIP was conducted at $580{ }^{\circ} \mathrm{C}$ and $100 \mathrm{MPa}$ for 2 hours at a heat rate of $4^{\circ} \mathrm{C} / \mathrm{min}$. The SS 304 canning plates were removed by electro-discharge machining. Three thermocouples were installed at each mockup to measure

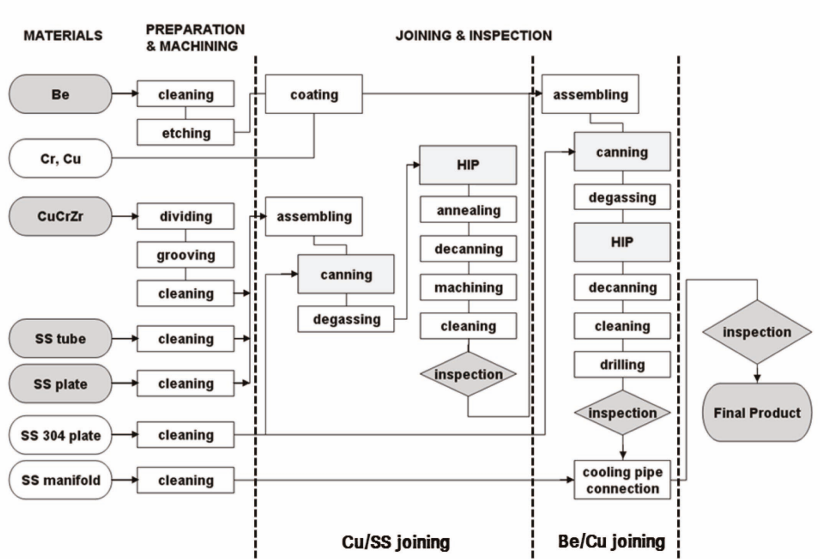

Fig. 2. General Procedure of the HIP for Be/Cu/SS Mockup

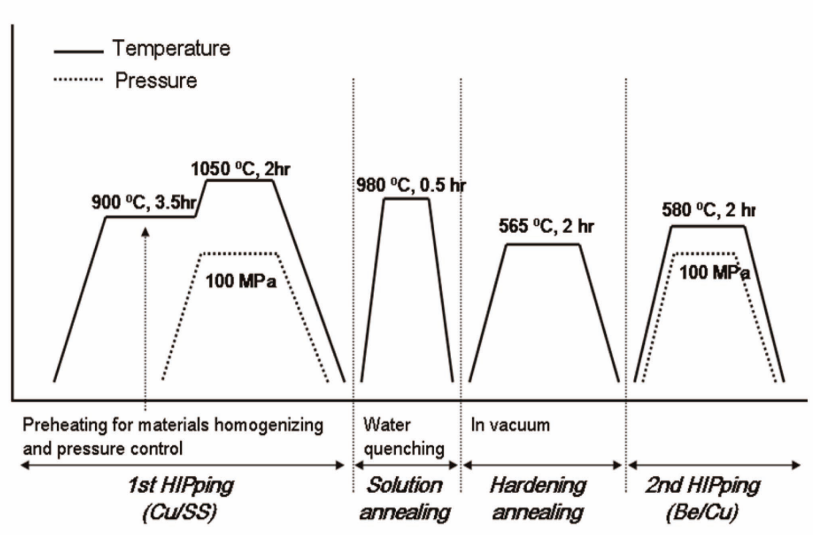

Fig. 3. Developed HIP Conditions for the FW Joining 
the temperature at an inner part of each mockup, and additional coolant pipes were welded to the mockups to install them at the KoHLT-1 facility as shown in Fig. 4.

Shear tests were performed with shear specimens, which were fabricated under the same conditions as the mockups. Their dimensions were 50-mm-long and 10mm-wide, and the other conditions followed ASTM B432, ASTM A265, and JIS G0601. The loading speed was 0.5 $\mathrm{mm} / \mathrm{min}$ at room temperature. Figure 5 shows the microstructure of a $\mathrm{Be} / \mathrm{Cu}$ joint, and there was no pore or crack. A diffusion layer formed between the $\mathrm{Be} / \mathrm{Cu}$ joint with a thickness of about $10 \mu \mathrm{m}$. Figure 6 shows the shear test results for three specimens, which were obtained from the different locations, namely, a corner and the center region. The average values were from $125 \mathrm{MPa}$ to $180 \mathrm{MPa}$, and the samples with the $1 \mu \mathrm{m} \mathrm{Cr} / 10_{\mu \mathrm{m}} \mathrm{Cu}$ interlayer showed the lowest value, which was higher than the minimum requirement (about $100 \mathrm{MPa}$ ).

To search for any defect in the $\mathrm{Be} / \mathrm{Cu}$ joints, a nondestructive test was performed using a flat-type ultrasonic probe with a $10 \mathrm{MHz}$ frequency and a 0.25 inch diameter. A calibration block simulating the first-wall panel was fabricated as shown in Fig. 7. Four artificial defects with different hole sizes were applied at the bonding interfaces. For the calibration of the used method, data was acquired from the beryllium side of the block, and the same probe
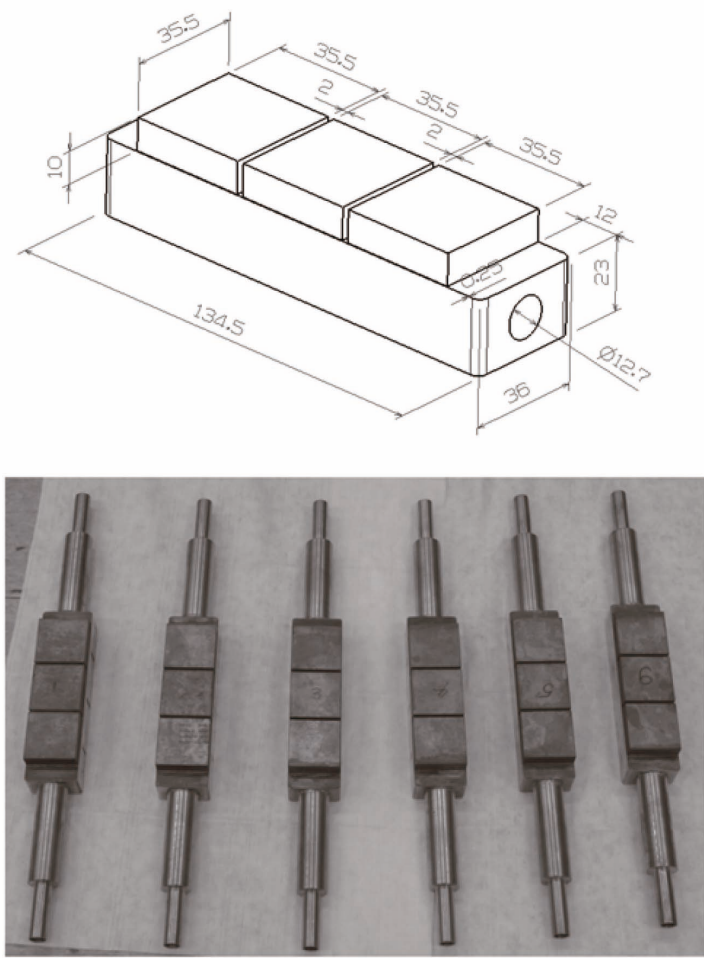

Fig. 4. Schematic and Photos of the Mockups for the HHF Test
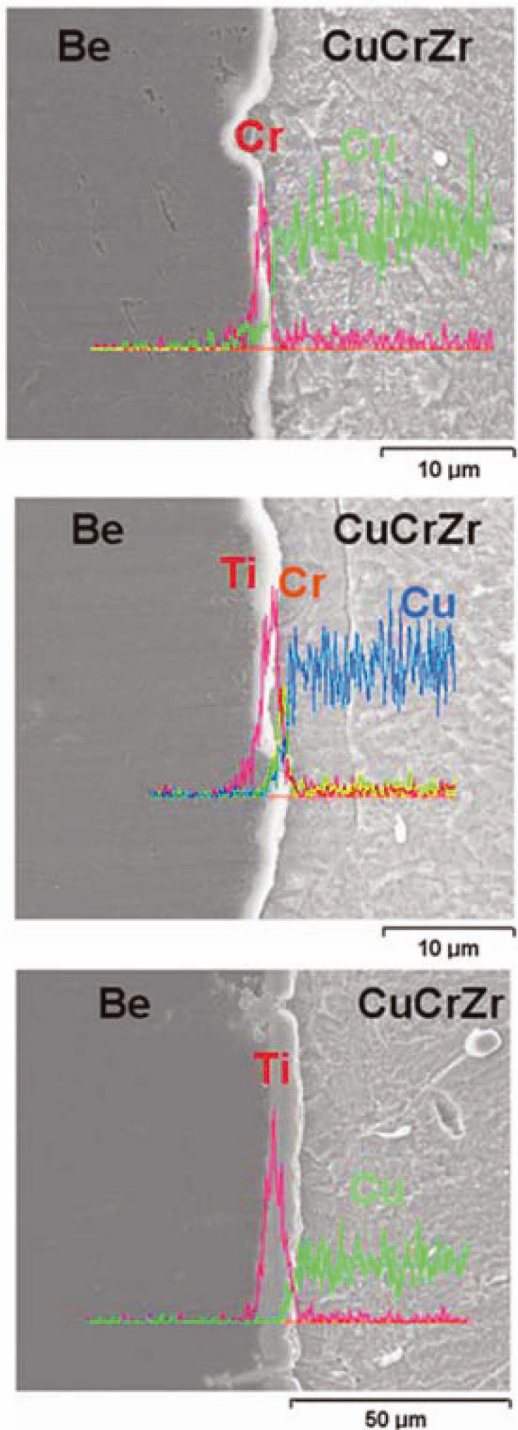

Fig. 5. Microstructure Observation with $\mathrm{Be} / \mathrm{CuCrZr}$ Joints

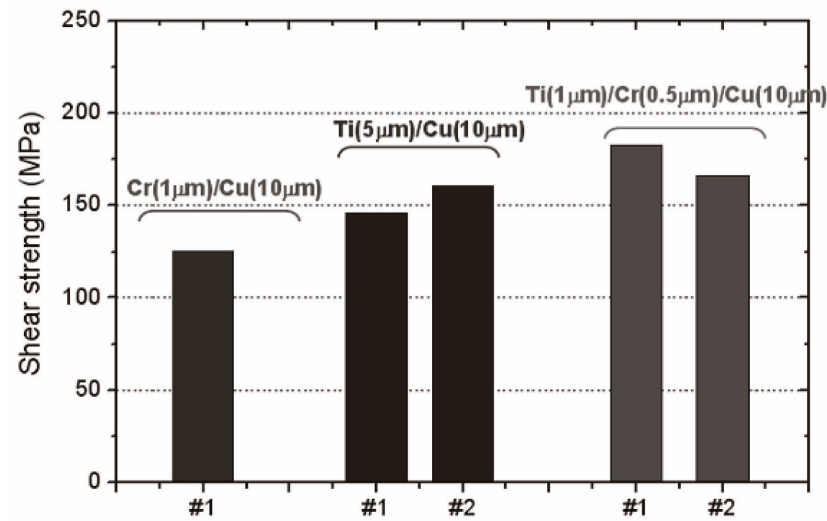

Fig. 6. Shear Test Results for the $\mathrm{Be} / \mathrm{CuCrZr}$ Samples 

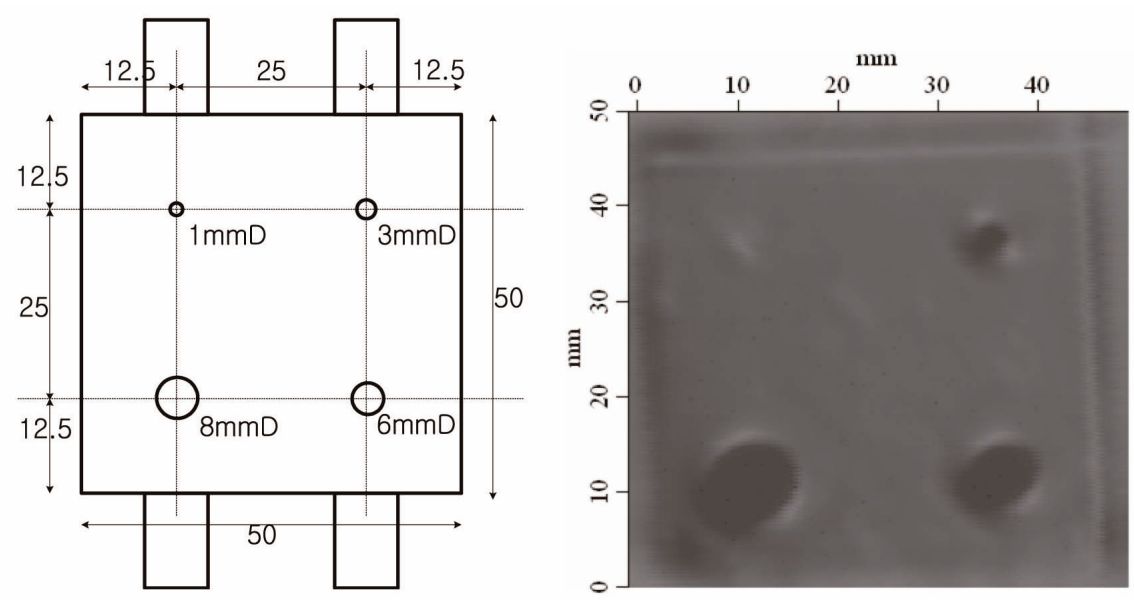

Fig. 7. Drawing and C-Scan Image of the Calibration Block

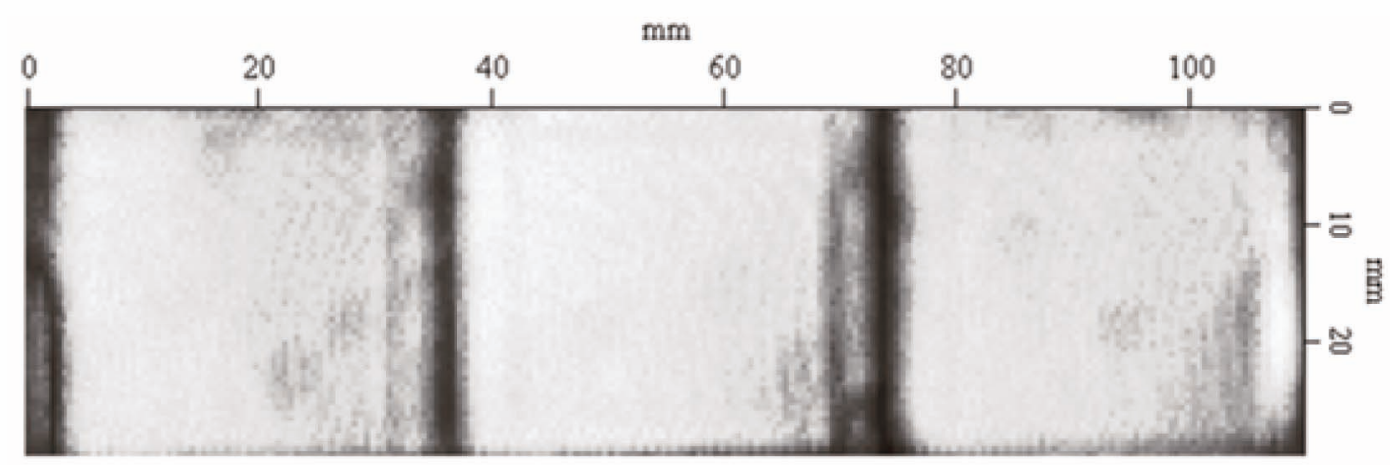

Fig. 8. C-Scan Image of Ultrasonic Test for the Mock-Up No. 1

scanned across the sample. As seen in the figure the smallest defect size which can be detected is about $2 \mathrm{~mm}$ in diameter. The fabricated $35 \times 35 \times 3$ mockups were scanned by the same method, and one of the scanned images is shown in Fig. 8. No defect was found in any of the $\mathrm{Be} / \mathrm{Cu}$ interfaces of the mockups.

\section{HIGH HEAT FLUX TEST}

\subsection{Preliminary Analysis}

Preliminary analyses were carried out to specify the test conditions and to predict the fatigue lifetime of the mockups taking the ITER operation conditions into consideration [1]. In this test, only the surface heat flux condition was considered, and the water condition was changed according to water supply system of the test facility, KoHLT-1, in which room temperature and atmospheric pressure conditions were used.
To reduce the test time, an accelerated test was carried out in which the heat flux was increased up to $1.0 \mathrm{MW} / \mathrm{m}^{2}$, at which the heat flux was determined to avoid the evaporating temperature of a Be tile. Analysis was performed using 3-dimensional modeling and the following boundary conditions of ANSYS-11 including ANSYSCFX for thermal-hydraulic analysis and following the boundary condition of ANSYS-mechanical for the thermomechanical analysis. A uniform heat flux of $1.0 \mathrm{MW} / \mathrm{m}^{2}$ was applied to the Be tiles during the heating phase, and the coolant flowed continuously during the heating and cooling phases. The simulation and test conditions are summarized in Table 1. Because it takes time to heat up and cool down the graphite heater, The meaning of the phrase is that it takes time about $30 \mathrm{sec}$ to turn on or turn off the heater. Moreover, since it takes time to heat the mockup to the saturated temperature and to recover its initial temperature, cooling times of $120 \mathrm{sec}$ and $60 \mathrm{sec}$ duration were used. Three cycles were simulated using these heating conditions, and it was confirmed that there 
Table 1. Test Conditions

\begin{tabular}{c|c}
\hline Parameters & Test conditions \\
\hline Water conditions & $0.2 \mathrm{MPa}, 11^{\circ} \mathrm{C}, 1.211 \mathrm{~m} / \mathrm{sec}$ \\
\hline Duration time [sec] & $\begin{array}{c}30 \mathrm{sec} \text { heater on } / 120 \mathrm{sec} \text { holding } \\
30 \mathrm{sec} \text { heater off } / 60 \mathrm{sec} \text { cooling }\end{array}$ \\
\hline Surface heat flux $\left[\mathrm{MW} / \mathrm{m}^{2}\right]$ & 1.0 \\
\hline Tested cycles & 1,100 \\
\hline $\begin{array}{c}\text { Estimated number of cycles } \\
\text { to a failure by analysis }\end{array}$ & 1,350 \\
\hline
\end{tabular}
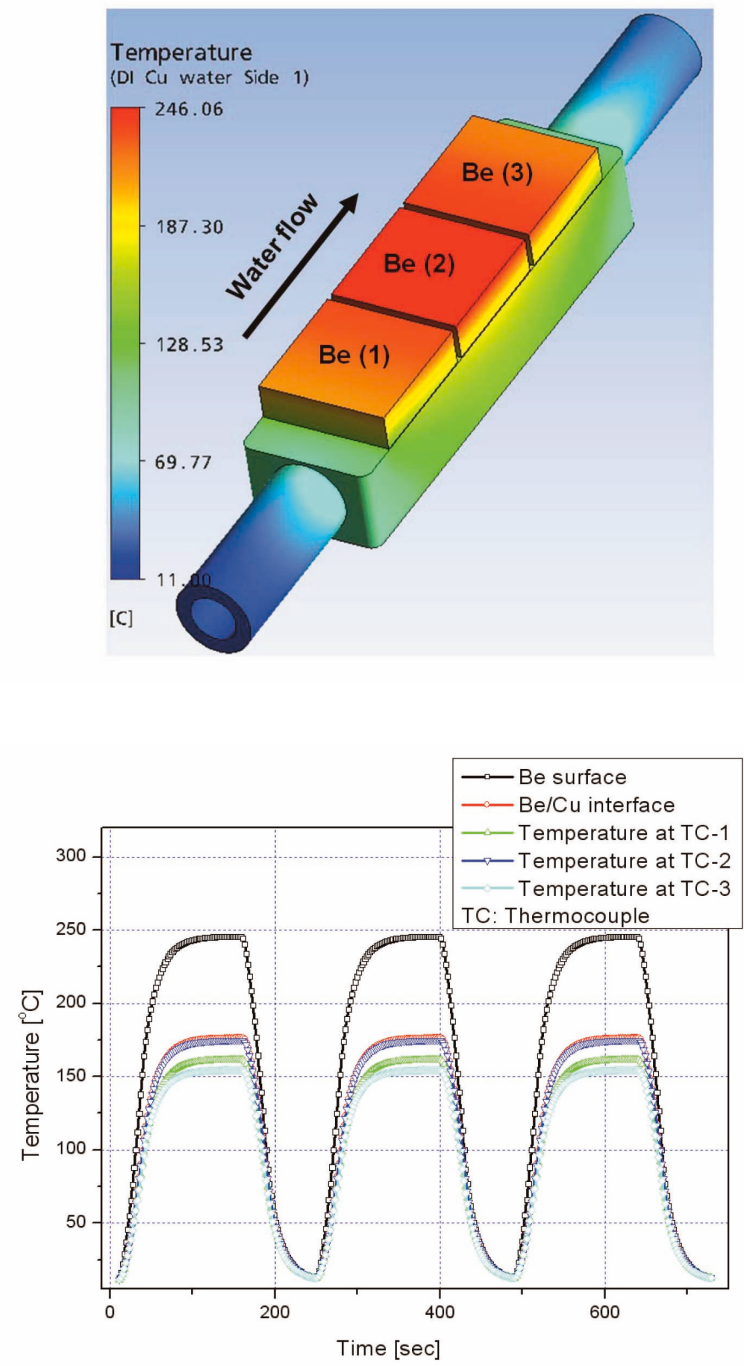

Fig. 9. Temperature Distribution at the end Heaitng of the $3^{\text {rd }}$ Cycle $(630 \mathrm{sec})$ and Evolution for 3 Cycles Under a $1.0 \mathrm{MW} / \mathrm{m}^{2}$ Heat Flux
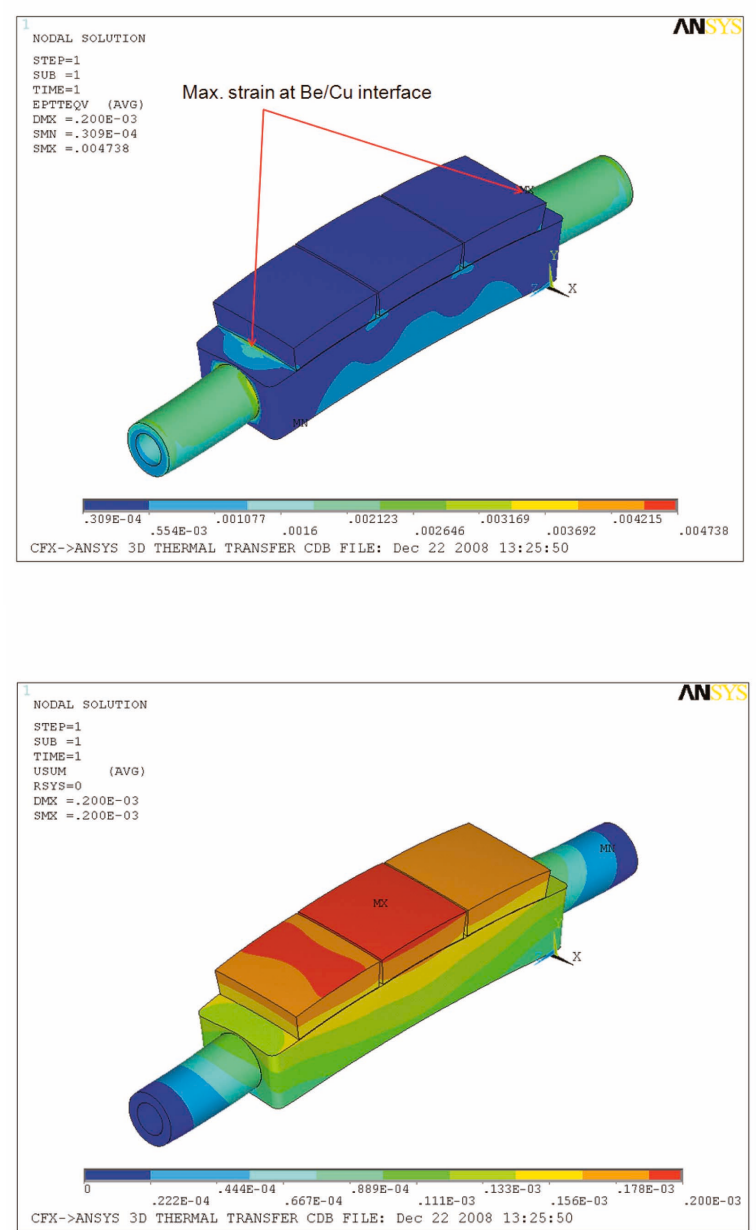

Fig. 10. Deformation and Strain Distribution at the end of the $3^{\text {rd }}$ Cycle Under a 1.0 MW/m² Heat Flux

were no temperature increases as cycles continued. The calculated temperature distributions of the mockups at the heating time of the third cycle $(630 \mathrm{sec})$ and evolutions for 3 cycles are shown in Fig. 9. To compare the measured temperatures during the test, temperatures were obtained at the same location with the installed thermocouples. The maximum temperature of the Be surface at this time was $246^{\circ} \mathrm{C}$. At this time, the temperature and meshes were used for a structural analysis with ANSYS-mechanical, and the deformation and strain distributions were obtained for each material as shown in Fig. 10. The maximum deformation at a Be tile was $0.2 \mathrm{~mm}$, and the maximum total strains were $0.4738 \%$ at a $\mathrm{Be} / \mathrm{Cu}$ interface, which indicates that the number of cycles to failure was about 1,350 cycles as shown in Fig. 11 [8]. The lifetime to failure of the $\mathrm{Cu}$ alloy under ITER operation conditions was 30,000 cycles, but the operation lifetime was about 12,000 cycles. Therefore, the minimum requirement to be tested in these mockups was determined to be 1,000 cycles. 


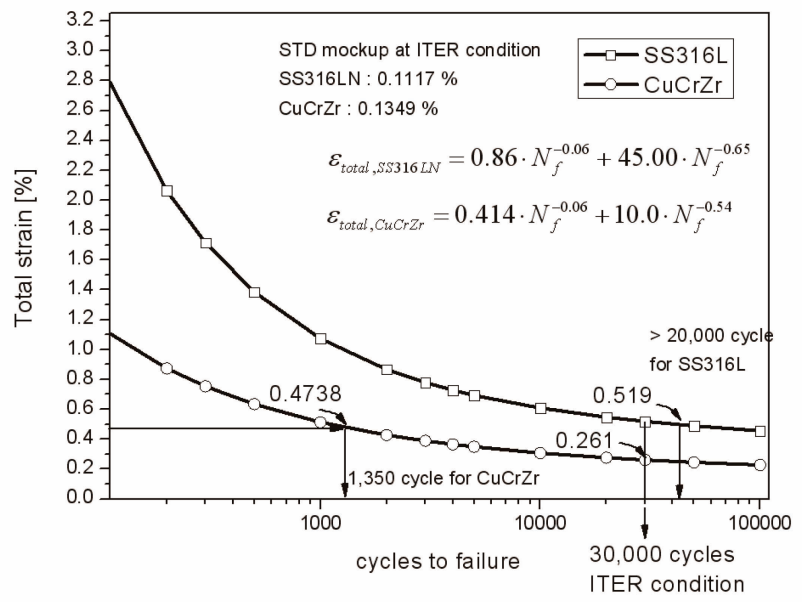

Fig. 11. Number of Cycles to a Failure at the $3^{\text {rd }}$ Heating Phase (at $40 \mathrm{sec}$ ) Under a $1.0 \mathrm{MW} / \mathrm{m}^{2}$ Heat Flux

\subsection{Test Facility}

Since an HHF test is essential for investigating the thermo-mechanical performance of the FW including the integrity of the HIP bonded interfaces, the fabricated mockups were tested at the KoHLT-1. This facility consists of a target assembly comprising a target mount and a graphite heater, a test chamber $(0.3 \mathrm{~m} \times 0.3 \mathrm{~m} \times 1.2 \mathrm{~m}$ with cooling jackets, a DC power supply, a water cooling system, a data acquisition system (DAS), and auxiliary systems (a beryllium evacuation system, a helium gas feeding system, and a diagnostics system). This first heat-load test facility was installed in the authorized laboratory equipped ventilation system with a Be filter to treat the Be toxic materials. The water cooling system can supply the coolant with $0.2 \mathrm{MPa}$ pressure and a $0.5 \mathrm{~kg} / \mathrm{sec}$ flow rate. The target assembly was designed to mount the various mockups of different sizes, and a graphite heater was positioned between two mockups with a gap of 2 to $5 \mathrm{~mm}$ using R8710 grade graphite (SGL Carbon Group). The applied electrical power $(40 \mathrm{~kW})$ to the heater was adjusted by the data control system, and output power was traced by DAS. Figure 12 shows the overall operative equipment of the KoHLT-1.

For the HHF testing of the fabricated mockups, graphite heaters were fabricated such that the dimensions of the active heating region were $35 \mathrm{~mm}$ x $100 \mathrm{~mm}$ considering the mockup sizes and power supply. Two mockups were installed with a gap from the heater as shown in Fig. 13, and then water cooling pipes were connected to the mockups. When a current of 290 A was applied, the temperature of the heater increased up to $2,300{ }^{\circ} \mathrm{C}$. The heat flux near the heater increased up to $1.0 \sim 1.5 \mathrm{MW} / \mathrm{m}^{2}$, depending on the distance from the mockup to the heater. In this test, the distance was fixed at $2 \mathrm{~mm}$ to obtain the heat flux of $1.0 \mathrm{MW} / \mathrm{m}^{2}$.
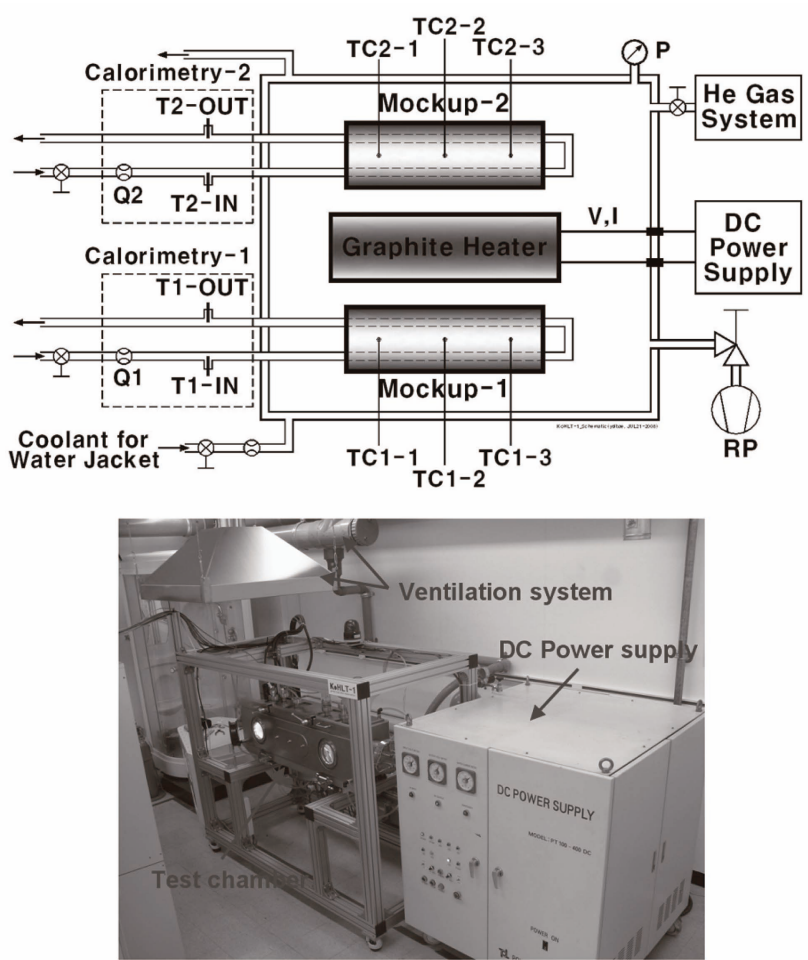

Fig. 12. Schematic Diagram and Photograph of KoHLT-1

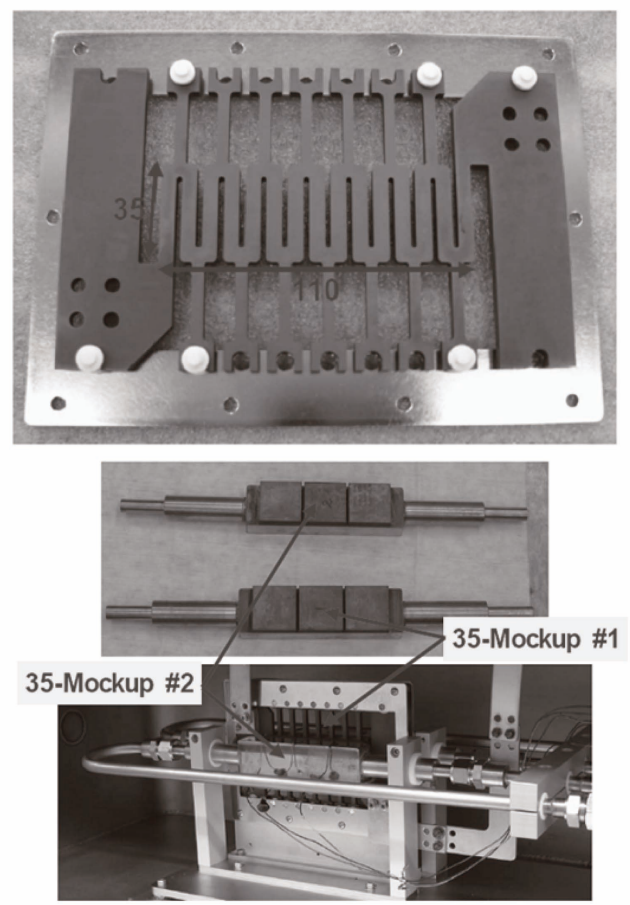

Fig. 13. Photographs of the Graphite Heater and Installed Mockups in the KoHLT-1 
Table 2. Summary of the Manufactured Mockups and HHF Test Results

\begin{tabular}{c|c|c|c}
\hline Mockup no & Interlayers & Tested cycles & Remark \\
\hline 1 & $1 \mu \mathrm{mCr} / 10 \mu \mathrm{mCu}$ & 862 & Success \\
\hline 2 & $1 \mu \mathrm{mCr} / 10 \mu \mathrm{mCu}$ & 862 & S tile detached during the screening test \\
2 tiles were detached by discharge
\end{tabular}

\subsection{Test Results}

Based on the results of the preliminary analysis, and following the test conditions shown in Table 1 , the tests were performed with each mockup, and the results are summarized in Table 2. During the tests, all temperature data was stored and monitored to check for a sudden temperature increase caused by delamination or irregular heat flux. First, mockups 1 and 2 were tested. One of the Be tile in mockup 1 was detached during the screening test, in which the heat flux increased slowly before reaching the target heat flux 1.0 MW/m². After 862 cycles, the power supply showed irregular operation, and the mockup temperatures increased rapidly. At that point, we stopped the test, and the mockups were visually investigated. Some of the Be tiles in the mockups were detached with burning caused by discharge between the heater and the mockups as shown in Fig. 14. Mockups 3 and 4 were installed to replace the first two mockups along with a new graphite heater, and then, the test continued. The tests were performed up to 1,100 cycles for $1.0 \mathrm{MW} / \mathrm{m}^{2}$ heat flux without any sudden increase in temperature. Tests with mockups 5 and 6 showed the same results. The measured temperatures showed good agreement with the expected temperatures as shown in Fig. 15. Except mockups 1 and 2, no evidence of delamination or failure was found after an evacuation of the mockups as shown in Fig. 16.

\section{CONCLUSION}

To develop a manufacturing method for the ITER blanket FW and to prepare for the procurement qualification program, six Be/Cu mockups were fabricated with $1 \mu \mathrm{m}$

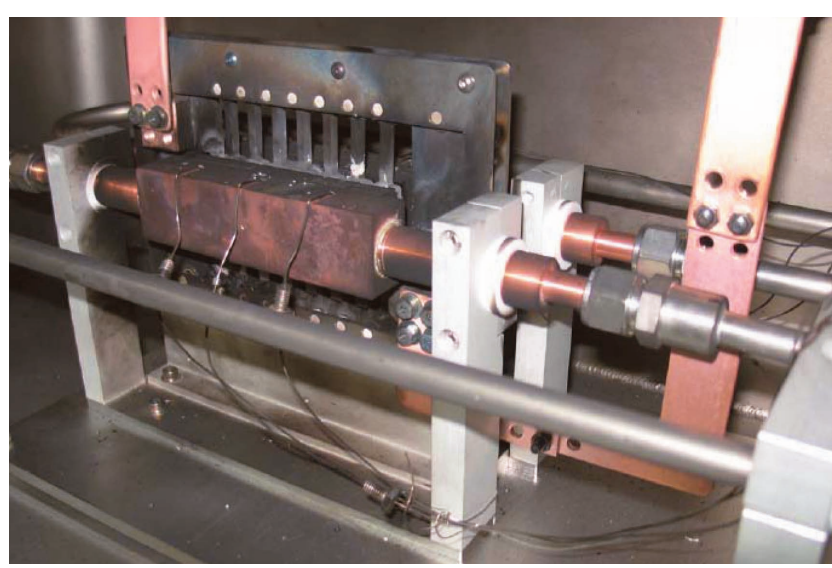

Fig. 14. Photograph of the Be Tile Detachment by Discharge

$\mathrm{Cr} / 10{ }_{\mu \mathrm{m}} \mathrm{Cu}, 1{ }_{\mu \mathrm{m}} \mathrm{Ti} / 0.5 \mu \mathrm{m} \mathrm{Cr} / 10_{\mu \mathrm{m}} \mathrm{Cu}$, and $5 \mu \mathrm{m} \mathrm{Ti} / 10_{\mu \mathrm{m}} \mathrm{Cu}$ interlayers using the previously determined HIP conditions (580 ${ }^{\circ} \mathrm{C}$ and $100 \mathrm{MPa}$ for 2 hours). The mechanical test results showed that the average shear strength was 125 $\mathrm{MPa}$ to $180 \mathrm{MPa}$ and the samples with the $1_{\mu \mathrm{m}} \mathrm{Cr} / 10_{\mu \mathrm{m}}$ $\mathrm{Cu}$ interlayer showed the lowest value. No defect or delamination was found in the joints of the mockups by the developed ultrasonic test probe. The joints were tested in a graphite heater facility, KoHLT-1, under $1.0 \mathrm{MW} / \mathrm{m}^{2}$ heat flux and the given water cooling conditions to verify their integrity. We used the ANSYS code to determine the test conditions and to obtain the temperature and strain distributions. With the obtained strain of the $\mathrm{Cu}$ in the joint, the test requirement, that is, the number of cycles to failure, was determined to be 1,000 cycles. Four mockups using 


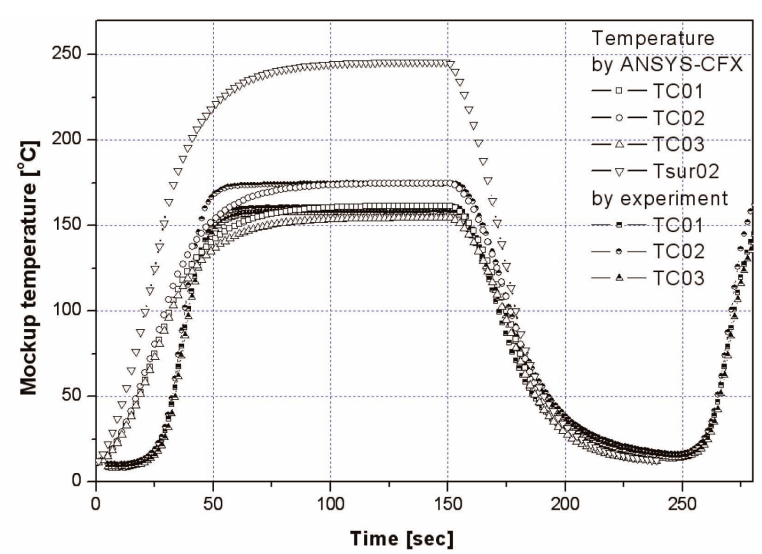

Fig. 15. Measured Temperatures and Their Comparison with the Analysis Ones

$1 \mu \mathrm{m} \mathrm{Ti} / 0.5 \mu \mathrm{m} \mathrm{Cr} / 10 \mu \mathrm{m} \mathrm{Cu}$ and $5 \mu \mathrm{mTi} / 10 \mu \mathrm{m} \mathrm{Cu}$ interlayers survived up to 1,100 cycles more than the required cycles. However, one of the Be tiles in the other two mockups using a $1 \mu \mathrm{m} C \mathrm{r} / 10 \mu \mathrm{mCu}$ interlayer was detached during the screening test, and others were detached by discharge after 862 cycles. The integrity of the joints using the proposed interlayers was demonstrated by the HHF test, but the other interlayer requires more study before it can be used for the joining of $\mathrm{Be}$ to $\mathrm{Cu}$. Moreover, it was confirmed that the measured temperatures agreed well with the analysis temperatures, which were used to estimate the lifetime and that the developed facility showed its capability of the long time operation.

\section{ACKNOWLEDGMENT}

This research was supported by National R\&D Program through the National Research Foundation of Korea (NRF) funded by the Ministry of Education, Science and Technology \& Ministry of Knowledge Economy.

\section{REFERENCES}

[1] A. Cardella, et. al., "Technical Basis for the ITER EDA plasma facing components," Fusion Eng. Des., 39-40, 377-384 (1998).

[2] J. Y. Park et. al., "Optimization of joining condition for ITER first wall fabrication," J. Korean Phys. Soc., 49, S442-S446 (2006).

[3] D. W. Lee et. al., "Development of Fabrication and Qualification Methods for the First Wall of the International

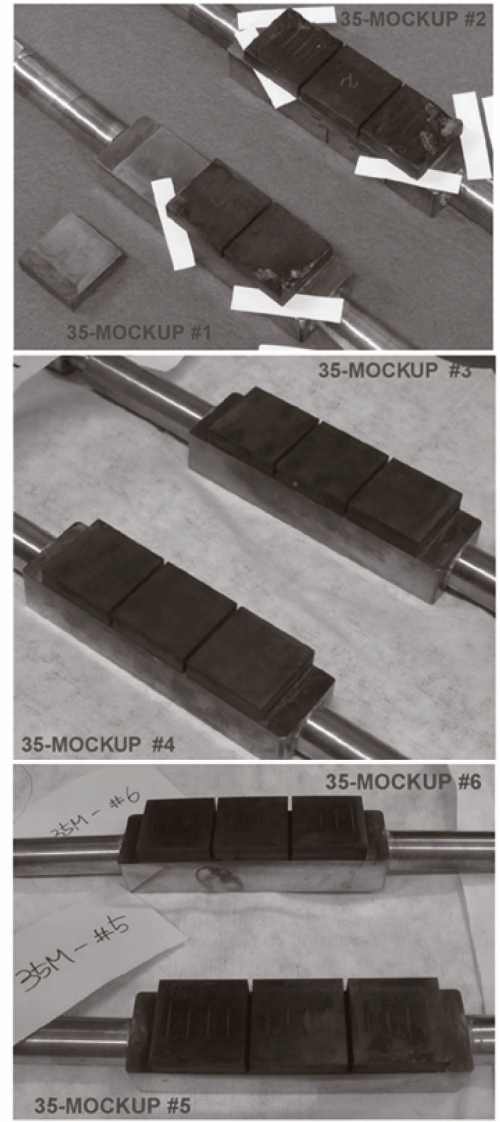

Fig. 16. Photo of the Tested Mockups

Thermonuclear Experimental Reactor (ITER)," J. Korean Phys. Soc., 51, 1210-1215 (2007).

[4] D. W. Lee et. al., "High heat flux test with HIP bonded $\mathrm{Cu} / \mathrm{SS}$ mockups for the ITER first wall," Fusion Eng. Des., 83, 1038-1043 (2008).

[ 5 ] D.W. Lee, et. al., "High Heat Flux Test with HIP Bonded $\mathrm{Be} / \mathrm{Cu} / \mathrm{SS}$ Mockups for the ITER First Wall," Fusion Eng. Des., 84, 1160-1166 (2009).

[6] D.W. Lee, et. al., "High Heat Flux Test with HIP Bonded 50x50 Be/Cu Mockups for the ITER First Wall," Fusion Sci. Tech., 56, 48-51 (2009).

[ 7 ] J. Y. Park et. al., "Fabrication of Be/CuCrZr/SS mockups for ITER first wall," Fusion Eng. Des., 84, 1468-1171 (2009).

[ 8 ] ITER Material Properties Handbook, File code: ITERAA02-2402. 